\title{
GENDER DIFFERENCES IN HEALTH-RELATED QUALITY OF LIFE AMONG ESTONIAN ADOLESCENTS: A 6-MONTH FOLLOW-UP
}

\author{
RoOmet Vitra, ANDre KoKa \\ Faculty of Exercise and Sport Sciences, University of Tartu, Tartu, Estonia
}

\begin{abstract}
This study aimed to determine the differences between boys and girls in the health-related quality of life (HRQoL) and its domains of physical health, emotional-, social-, and school-related functioning over a six-month period. Six hundred and forty seven Estonian secondary school students participated in the study, of whom 401 ( 177 boys and 224 girls; age $13.60 \pm 0.63$ years) filled in the HRQoL questionnaire (PedsQL ${ }^{\text {ra }} 4.0$ Generic Core Scales) on three occasions: baseline, 3-month, and 6-month follow-ups. To analyse the changes in HRQoL among boys and girls over a six-month period, repeated measures ANOVA was performed. The results revealed that boys scored significantly higher compared to girls on emotional functioning at all three time points over a six-month period. As for total score of HRQoL, and physical and psychosocial health, boys scored significantly higher than girls only on the first and second measurements. No significant changes in total score of HRQoL as well as its domains were followed in boys or girls between baseline, 3-month, and 6-month follow-ups. The lower perceptions of total score of HRQoL as well as its domains of physical health, emotional functioning, and psychosocial health among girls in Estonia over a six month period support the findings of previous longitudinal studies.
\end{abstract}

Keywords: adolescence, longitudinal study, physical health, psychosocial health, PedsQL $L^{\mathrm{Tm}} 4.0$ Generic Core Scales

\section{INTRODUCTION}

The topics pertaining health-related quality of life (HRQoL) have received much attention in both clinical [10] and health-related surveys [5]. Studies carried out on healthy children are mainly necessary because the quality of life 
of children and adolescents is directly related to their quality of life in adulthood [3].

One of the most commonly used questionnaire assessing the HRQoL with its domains of physical, emotional, social and school-related functioning in children and youngsters is the PedsQL ${ }^{\mathrm{max}} 4.0$ Generic Core Scale [14], which includes both self-reports and parents' opinions of their children in the following age groups: 5-7, $8-12$ and $13-18$ years $[15,11]$. The HRQoL in children aged 2-4 years is evaluated only on the basis of their parents' proxyreports. Several studies have shown that the questionnaire is valid and reliable in measuring the HRQoL of schoolchildren as well as in population surveys $[11,12,13,16]$.

Cross-sectional studies have shown that HRQoL of girls in their early teenage years is significantly lower than that of boys, being mainly evident in the physical and psychological aspects (i.e., mood and emotions) of HRQoL $[2,3,4,16]$. In addition, the few long-term studies carried out have revealed that the changes occurring in early teenage years have a negative impact on HRQoL and all of its domains, especially in girls [7, 8]. Palacio-Vieira et al. [8], for example, studied HRQoL of Spanish children and adolescents aged 11-21 years, and found that the especially drastic negative changes occurred in the groups of girls aged 13-17 within a three-year study period. To date, there is no evidence of studies that have longitudinally observed the perceptions of HRQoL in the most sensitive age group (i.e. adolescents aged 13-14) in Eastern European countries, such as Estonia.

The main aim of the study was to establish gender differences in the total score of HRQoL and its domains of physical, psychological, social, and schoolrelated functioning among Estonian adolescents over a six-month period. The hypothesis of the study was that the perceptions of physical and psychological health aspects of HRQoL will be significantly higher among boys than those of girls over a six-month period.

\section{MATERIALS AND METHODS}

\section{Participants and procedures}

Secondary school students $(n=647)$ from a town of 100,000 inhabitants located in southeast of Estonia took part in the first data collection. The first data collection was carried out one month after the beginning of school year (Time 1 - October 2009). The second data collection was administered three months later (Time 2 - January 2010) and the third data collection was carried out when the school year was drawing to a close (Time 3 - April 2010). In 
total, 576 students took part in the second and 497 students in the third data collection. The 401 students ( 177 boys and 224 girls; age $13.60 \pm 0.63$ years) completed the questionnaire at all three time points. Students' dates of birth and gender were used as matching indices. The independent samples t-tests were conducted on the mean scores of each study variable to test for possible differences between students who completed the questionnaire at all three time points and those who dropped out. No significant differences emerged on the study variables, except on emotional functioning revealed that students who dropped out (73.88 \pm 20.16$)$ from the study exhibited significantly $(t=2.13$, $\mathrm{p}<0.05)$ higher score compared to students who completed the questionnaire at all three time points $(70.37 \pm 15.44)$. This suggests that cautious should be exercised when interpreting results concerning the emotional functioning domain of HRQoL.

Prior to data collection, permission to carry out the study was obtained from the head teachers of all schools. The informed consent was obtained from the participants and their parents via a letter sent home with each child. Parents' permission was considered approved if they did not send the letter back to the school. No letters with refusal were returned.

\section{Measures}

HRQoL: The PedsQL ${ }^{\text {tx }} 4.0$ Generic Core Scales [14], adapted into Estonian by Viira and Koka [16], was used to assess participants' perceptions of HRQoL with domains of physical health ( 8 items, e.g., "It is hard for me to walk more than one block"), emotional functioning ( 5 items, e.g., "I worry about what will happen to me"), social functioning (5 items, e.g., "Other kids tease me"), school-related functioning ( 3 items, e.g., "I have trouble keeping up with my schoolwork"), days missed from school due to illness ( 2 items, e.g., "I miss school to go to the doctor or hospital"), and psychosocial health that includes social, emotional and school functioning subscales. Participants were asked to indicate how much of a problem has this been during the past one month on a 5-point scale ranging from 0 (never a problem) to 4 (almost always a problem). Prior to data analysis items were reversed-scored and linearly transformed to a 0 to 100 scale (i.e., $0=100,1=75,2=50,3=25$, and $4=0$ ). In the present study, the Cronbach's alphas for total score of HRQoL and its dimensions of physical health, psychosocial health, emotional functioning, social functioning, schoolrelated functioning, days missed from school due to illness at time 1 were 0.87 , $0.77,0.84,0.78,0.80,0.68$, and 0.40 , respectively; at time 2 were $0.89,0.82$, $0.86,0.79,0.82,0.70$, and 0.59 , respectively; and at time 3 were $0.92,0.86,0.90$, $0.83,0.87,0.77$, and 0.65 , respectively. 


\section{Statistical analysis}

Data were analysed using SPSS 17.0 for Windows. Two-way analysis of variance (ANOVA) for repeated measures with time (baseline, 3-month, and 6-month follow-ups) as within subject factor and gender (boys, girls) as between subject factor was used to analyse the changes in the total score of HRQoL as well as its domains of physical health, psychosocial health, social functioning, emotional functioning, school-related functioning, and days missed from school due to illness. Significant main effects of time were further analysed using paired samples t-tests with Bonferroni correction. Since three paired samples t-tests were performed, the conventional significance level of 0.05 was set at $\mathrm{p}<0.017$ in order to prevent Type I error. Significant main effects of gender were further analysed using independent samples $t$-tests at each time points.

\section{RESULTS}

\section{Gender differences in total score of HRQoL over a 6-month follow-up}

Results of the ANOVA for repeated measures indicated that there was a significant main effect of time $\left(\mathrm{F}_{1,87,747,13}=4.58, \mathrm{p}<0.01, \eta_{\mathrm{p}}{ }^{2}=0.01\right)$ and gender $\left(\mathrm{F}_{1,399}=11.53, \mathrm{p}<0.001 ; \eta_{\mathrm{p}}{ }^{2}=0.03\right)$, but not significant interaction between time and gender $\left(\mathrm{F}_{1,87,747,13}=1.73, \mathrm{p}>0.05, \eta_{\mathrm{p}}{ }^{2}=0.004\right)$. For both boys and girls, after the Bonferroni correction, paired samples t-tests did not revealed statistically significant changes between baseline, 3-month, and 6-month follow-ups. Independent samples t-tests indicated that boys scored significantly higher than girls in total score of HRQoL at time 1 (boys $75.43 \pm 12.18$ vs. girls $70.30 \pm 12.45$, $\mathrm{t}=4.14, \mathrm{p}<0.001$ ) and time 2 (boys $75.13 \pm 12.89$ vs. girls $71.46 \pm 12.81, \mathrm{t}=2.84$, $\mathrm{p}<0.01$ ), but not at time 3 (boys $72.92 \pm 16.30$ vs. girls $70.07 \pm 13.79, \mathrm{t}=1.89$, $\mathrm{p}>0.05$ ) (Figure 1A).

\section{Gender differences in physical health domain of HRQoL over a 6-month follow-up}

Results of the ANOVA for repeated measures revealed significant main effect of time $\left(\mathrm{F}_{1,90,759,90}=5.23, \mathrm{p}<0.01, \eta_{\mathrm{p}}{ }^{2}=0.01\right)$ and gender $\left(\mathrm{F}_{1,399}=10.66\right.$, $\left.\mathrm{p}<0.001 ; \eta_{\mathrm{p}}{ }^{2}=0.03\right)$, but not significant interaction between time and gender $\left(\mathrm{F}_{1,90,759,90}=1.03, \mathrm{p}>0.05, \eta_{\mathrm{p}}{ }^{2}=0.003\right)$. Again, for both boys and girls paired samples t-tests did not revealed statistically significant changes between baseline, 3-month, and 6-month follow-ups. Independent samples t-tests indicated that boys scored significantly higher than girls in physical health at time 1 (boys $76.61 \pm 15.57$ vs. girls $70.95 \pm 14.32, \mathrm{t}=3.78, \mathrm{p}<0.001$ ) and time 2 (boys 
$76.04 \pm 16.69$ vs. girls $71.88 \pm 15.13, \mathrm{t}=2.61, \mathrm{p}<0.01$ ), but not at time 3 (boys $73.38 \pm 19.11$ vs. girls $69.95 \pm 16.64, t=1.92, p>0.05$ ) (Figure 1B).

\section{Gender differences in psychosocial health domain of HRQoL over a 6-month follow-up}

Results of the ANOVA for repeated measures revealed significant main effect of time $\left(\mathrm{F}_{1,87,744,66}=4.02, \mathrm{p}<0.01, \eta_{\mathrm{p}}{ }^{2}=0.01\right)$ and gender $\left(\mathrm{F}_{1,399}=13.66\right.$, $\left.\mathrm{p}<0.001 ; \eta_{\mathrm{p}}{ }^{2}=0.03\right)$, but not significant interaction between time and gender $\left(F_{1,87,744,66}=2.39, p>0.05, \eta_{p}{ }^{2}=0.006\right)$. Paired samples t-tests, however, did not revealed statistically significant changes between baseline, 3-month, and 6-month follow-ups for both boys and girls. Independent samples t-tests indicated that boys scored significantly higher than girls in psychosocial health at time 1 (boys $77.46 \pm 13.15$ vs. girls $71.45 \pm 13.30, t=4.52, \mathrm{p}<0.001$ ) and time 2 (boys $77.03 \pm 13.84$ vs. girls $72.86 \pm 13.74, \mathrm{t}=3.17, \mathrm{p}<0.01$ ), but not at time 3 (boys $74.55 \pm 17.05$ vs. girls $71.49 \pm 14.89, \mathrm{t}=1.92, \mathrm{p}>0.05$ ) (Figure $1 \mathrm{C}$ ).

\section{Gender differences in emotional functioning domain of HRQoL over a 6-month follow-up}

Results of the ANOVA for repeated measures revealed significant main effect of gender $\left(\mathrm{F}_{1,399}=33.64, \mathrm{p}<0.001 ; \eta_{\mathrm{p}}{ }^{2}=0.09\right)$, but not of time $\left(\mathrm{F}_{1,95,778,66}=0.55\right.$, $\left.\mathrm{p}>0.05 ; \eta_{\mathrm{p}}{ }^{2}=0.001\right)$ nor significant interaction between time and gender $\left(\mathrm{F}_{1,95,778,66}=2.22, \mathrm{p}>0.05 ; \eta_{\mathrm{p}}{ }^{2}=0.006\right)$. Independent samples $\mathrm{t}$-tests indicated that boys scored significantly higher than girls in emotional functioning at time 1 (boys $76.50 \pm 18.33$ vs. girls $65.37 \pm 19.26, t=6.02, p<0.001$ ), time 2 (boys $75.37 \pm 13.15$ vs. girls $66.25 \pm 13.30, \mathrm{t}=4.78, \mathrm{p}<0.01$ ), and time 3 (boys $73.59 \pm 21.28$ vs. girls $66.25 \pm 19.66, \mathrm{t}=3.58, \mathrm{p}<0.01$ ) (Figure 1D).

\section{Gender differences in social functioning domain of HRQoL over a 6-month follow-up}

Results of the ANOVA for repeated measures revealed that there was no significant main effect of time $\left(\mathrm{F}_{1,91,762,96}=2.38, \mathrm{p}>0.05 ; \eta_{\mathrm{p}}{ }^{2}=0.006\right)$, gender $\left(\mathrm{F}_{1,399}=0.02, \mathrm{p}>0.05 ; \eta_{\mathrm{p}}{ }^{2}=0.0001\right)$, nor significant interaction between time and gender $\left(\mathrm{F}_{1,91,762,96}=1.38, \mathrm{p}>0.05 ; \eta_{\mathrm{p}}{ }^{2}=0.003\right)$ (Figure 1E). 


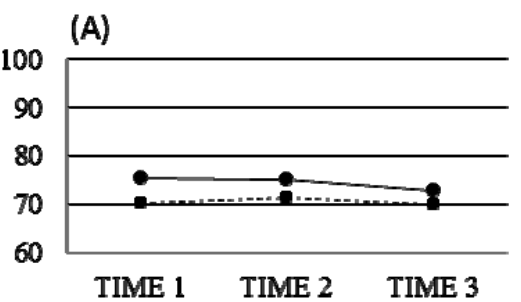

(B)
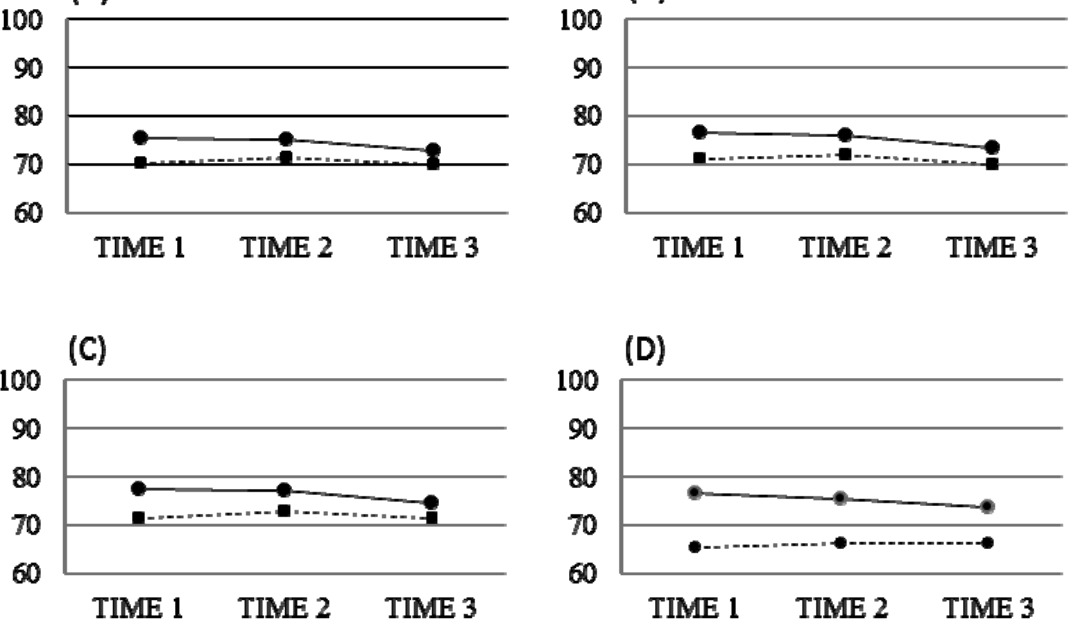

(E)
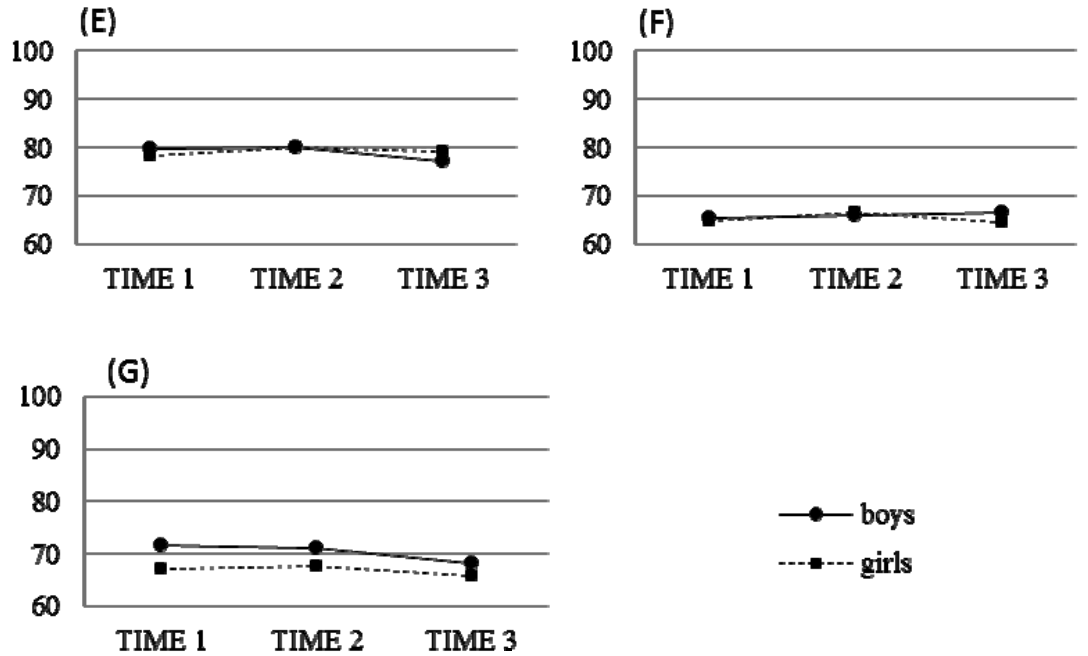

Figure 1. Gender differences in (A) total score of HRQoL and its domains of (B) physical health, (C) psychosocial health, (D) emotional functioning, (E) social functioning, $(F)$ school-related cognitive functioning, and $(G)$ days missed from school because of illness over a six month period. Note. The values between 0 and 60 have been omitted because all means were between 60 and 100 


\section{Gender differences in school-related functioning domain of HRQoL over a 6-month follow-up}

Results of the ANOVA for repeated measures revealed that there was no significant main effect of time $\left(\mathrm{F}_{2,798}=1.05, \mathrm{p}>0.05 ; \eta_{\mathrm{p}}{ }^{2}=0.003\right)$ gender $\left(\mathrm{F}_{1,399}=0.11\right.$, $\left.\mathrm{p}>0.05 ; \eta_{\mathrm{p}}{ }^{2}=0.0001\right)$ nor significant interaction between time and gender $\left(F_{2,798}=0.73, \mathrm{p}>0.05 ; \eta_{\mathrm{p}}{ }^{2}=0.002\right)$ (Figure $\left.1 \mathrm{~F}\right)$.

\section{Gender differences in days missed from school due to illness domain of HRQoL over a 6-month follow-up}

Results of the ANOVA for repeated measures revealed significant main effect of time $\left(\mathrm{F}_{2,798}=3.32, \mathrm{p}<0.05, \eta_{\mathrm{p}}{ }^{2}=0.008\right)$ and gender $\left(\mathrm{F}_{1,399}=4.80, \mathrm{p}<0.05\right.$; $\left.\eta_{\mathrm{p}}{ }^{2}=0.01\right)$, but not significant interaction between time and gender $\left(\mathrm{F}_{2,798}=0.41\right.$, $\left.\mathrm{p}>0.05, \eta_{\mathrm{p}}{ }^{2}=0.001\right)$. Paired samples t-tests, however, did not revealed statistically significant changes between baseline, 3-month, and 6-month follow-ups for both boys and girls. Independent samples t-tests indicated that boys scored significantly higher than girls in days missed from school due to illness at time 1 (boys $71.75 \pm 19.76$ vs. girls $67.29 \pm 18.13, \mathrm{t}=2.35, \mathrm{p}<0.05$ ), but not at time 2 (boys $71.19 \pm 20.29$ vs. girls $67.69 \pm 19.42, \mathrm{t}=1.75, \mathrm{p}>0.05$ ) and time 3 (boys $68.36 \pm 23.80$ vs. girls $65.85 \pm 19.01, \mathrm{t}=1.18, \mathrm{p}>0.05$ ) (Figure $1 \mathrm{G}$ ).

\section{DISCUSSION}

The aim of the study was to analyse gender differences in HRQoL among Estonian adolescents aged 13-14 years over a period of six months. As there were no significant changes in the mean scores of both boys and girls between baseline and two follow-ups, the following discussion focuses on gender differences. Our results showed gender differences in the total score of HRQoL and its domains of physical health, psychosocial health, emotional functioning, and absence from school due to an illness.

It is especially remarkable that within the six-month period, the mean score of emotional functioning aspect of HRQoL were consistently and statistically significantly higher in boys than in girls. These results are consistent with previous cross-sectional $[1,3,16]$ and longitudinal studies $[2,8]$. According to several researchers $[6,9]$, the causes of significantly lower scores on emotional functioning aspect of HRQoL in girls lie in extensive hormonal changes in that age, resulting in increased levels of anxiety and thereby a significant drop in psychological quality of life. Furthermore, Kolip et al. [6] have stated that the way boys solve problems differs from girls. The latter authors have argued that upon emergence of problems girls become rather introverted whereas 
boys become extroverted, resulting in psychosomatic and mental deviances in early adolescence years.

As for the total score of HRQoL, physical health and psychosocial health, the mean scores of boys were significantly higher than those of girls on both the first and second measurement time, but not on the third time. Previous crosssectional $[1,3,16]$ and longitudinal $[2,8]$ studies have found similar results, i.e. the mean scores of boys tend to be considerably higher in the mentioned domains of HRQoL than those of girls. One of the most important reasons why girls perceive their HRQoL as relatively poor compared to boys lies in problems related to menstruation $[2,6]$. However, it is still debatable why the perception of HRQoL in most of its domains becomes more negative in boys in the second (i.e., six-month) follow-up of the study, so that differences in the mean scores between boys and girls are no longer statistically significant. The six-month follow-up of the study fell near the end of the school year (i.e., April), when preparations for the final exams begin. It is fairly likely that exams at the end of the school year are more stressful for boys than for girls, which could also contribute to the poorer perception of their HRQoL.

Although this study provided a first overview of the perceptions of healthrelated quality of life in adolescents over a six-month period in a post-Soviet country, such as Estonia, the study also has its limitations. The first limitation lies in the relatively small sample, thus reducing the level of generalizability at the country level. The second limitation concerns the focus on only 13-14-year-old adolescents. It would also be necessary to study longitudinally pre-pubertal children as well as younger and older adolescents. The third limitation pertains to the two-item subscale of days missed from school due to illness from the Peds $\mathrm{QL}^{\mathrm{Tw}} 4.0$, in particular the low internal consistency of the items. Thus, there is a real need to rephrase these two items in order to be sure both items measuring the same content. For example, Viira and Koka [16] have stated that although both statements assess the reasons for absence from school, one statement ("I miss school to go to the doctor or hospital.") does not necessarily reflect absences from school due to illness, as going to see a doctor may also be related to regular health checks.

In conclusion, the results of the study revealed that female adolescents in Estonia scored lower in most of the domains of HRQoL than those of boys during a six-month follow-up, confirming the both previous cross-sectional and longitudinal studies. 


\section{REFERENCES}

1. Amiri P, Ardekani EM, Jalali-Farahani S, Hosseinpanah F, Varni JW, Ghofranipour F, Montazeri A, Azizi F. (2010) Reliability and validity of the Iranian version of the Pediatric Quality of Life Inventory ${ }^{\mathrm{rm}} 4.0$ Generic Core Scales in adolescents. Qual Life Res, 19: 1501-1508

2. Benjet C, Hernandez-Guzman L. (2002) A short-term longitudinal study of pubertal change, gender, and psychological well-being of Mexican early adolescents. J Youth Adolescence, 31: 429-442

3. Bisegger C, Cloetta B, von Rueden U, Abel T, Ravens-Sieberer U, European Kidscreen Group. (2005) Health-related quality of life: gender differences in childhood and adolescence. Soc Prev Med, 50: 281-291

4. Cavallo F, Zambon A, Borraccino A, Raven-Sieberer U, Torsheim T, Lemma P. (2006) Girls growing through adolescence have a higher risk of poor health. Qual Life Res, 15: 1577-1585

5. Fryback DG, Dunham NC, Palta M, Hanmer J, Buechner J, Cherepanov D, Herrington SA, Hays RD, Kaplan RM, Ganiats TG, Feeny D, Kind P. (2007) US norms for six generic health related quality-of-life indexes from the National Health Measurement study. Med Care, 45: 1162-1170

6. Kolip P, Nordlohne E, Hurrelmann K. (1993) Der Jugendgesundheitssurvey. In: Kolip P, Hurrelmann K, Schnabel P-E (eds). Jugend und Gesundheit: Interventionsfelder und Präventionsbereiche. Weinheim: Juventa, 25-48

7. Meuleners LB, Lee AH. (2003) Adolescent quality of life: A school-based cohort study in Western Australia. Pediatr Int, 45: 706-711

8. Palacio-Vieira JA, Villalonga-Olives E, Valderas JM, Espallargues M, Herdman M, Berra S, Alonso J, Rajmil L. (2008) Changes in health-related quality of life (HRQoL) in a population-based sample of children and adolescents after 3 years of follow-up. Qual Life Res, 17: 1207-1215

9. Ravens-Sieberer U, Gosch A, Rajmil L, Erhart M, Bruil J, Power M, Duer W, Auquier P, Cloetta B, Czemy L, Mazur J, Czimbalmos A, Tountas Y, Hagquist C, Kilroe J, KIDSCREEN Group. (2007) The KIDSCREEN-52 quality of life measure for children and adolescents: Psychometric results from a cross-cultural survey in 13 European countries. Value Health, 11: 645-658

10. Valderas JM, Kotzeva A, Espallargues M, Guyatt G, Ferrans CE, Halyard MY, Revicki DA, Symonds T, Parada A, Alonso J. (2008) The impact of measuring patient-reported outcomes in clinical practice: A systematic review of the literature. Qual Life Res, 17: 179-93

11. Varni JW, Burwinkle TM, Seid M. (2006) The PedsQL ${ }^{\mathrm{ra}} 4.0$ as a school population health measure: Feasibility, reliability, and validity. Qual Life Res, 15: 203-215

12. Varni JW, Burwinkle TM, Seid M, Skarr D. (2003) The PedsQL ${ }^{\mathrm{Tx}} 4.0$ as a pediatric population health measure: Feasibility, reliability, and validity. Ambul Pediatr, 3: 329-341 
13. Varni JW, Limbers CA, Burwinkle TM. (2007) How young can children reliably and validly self-report their health related quality of life?: An analysis of 8,591 children across age subgroups with the PedsQL ${ }^{\text {ra }} 4.0$ Generic Core Scales. Health Qual Life Outcome, 5: 1-13

14. Varni JW, Seid M, Kurtin PS. (1999) The PedsQL ${ }^{\mathrm{Tx}}$ : Measurement model for the Pediatric Qualiti of Life Inventory. Med Care, 37: 126-139

15. Varni JW, Seid M, Kurtin PS. (2001) The PedsQL ${ }^{\mathrm{Tm}}$ 4.0: Reliability and validity of the Pediatric Qualiti of Life Inventory ${ }^{\mathrm{Ts}}$ Version 4.0 Generic Core Scale in healthy and patient populations. Med Care, 39: 800-812

16. Viira R, Koka A. (2011) Health-related quality of life of Estonian adolescents: reliability and validity of the PedsQL ${ }^{\mathrm{ra}} 4.0$ Generic Core Scales in Estonia. Acta Paediatr, 100: 1043-1047

\section{Correspondence to:}

Andre Koka

Institute of Sport and Coaching Sciences

Faculty of Exercise and Sport Sciences

University of Tartu

5 Jakobi Street, 51014 Tartu

Estonia

E-mail: andre.koka@ut.ee

tel: +3727375382 . 